\title{
Um polvo é igual a um pato? Sobre o impacto das variáveis fonológicas na avaliação do conhecimento metalinguístico ${ }^{1}$
}

\author{
Catarina Afonso \& Maria João Freitas \\ Faculdade de Letras da Universidade de Lisboa \\ \& Centro de Linguística da Universidade de Lisboa
}

\begin{abstract}
:
Most tools used to assess phonological awareness (PA) are not controlled from a phonological perspective. However, research available for different languages refers the impact of phonological variables in the assessment of this type of linguistic knowledge. In this paper, we will be focused on the impact of the prosodic variables word length, syllable constituency and word stress in the performance of tasks assessing Portuguese children's PA. A sample of 49 monolingual and typically developing Portuguese children was gathered ( 22 first graders and 27 third graders). Three tasks were used to assess syllable awareness ( 1 segmentation task, 1 identification task, 1 omission task); one segmentation task assessed the children's segmental awareness; another segmentation task assessed their awareness of syllable constituency. Although some studies report the effect of all prosodic variables mentioned above (see state of the art below), the results in this paper show a significant effect of syllable structure, lexical stimuli with branching onsets and branching rhymes being the most problematic, but no significant effects of word length or word stress. The results are an empirical contribution for the discussion of the aspects that need to be taken in to account to build PA assessment tools and to plan intervention in clinical and in educational contexts.
\end{abstract}

Keywords: phonological awareness, prosody, syllable structure, word length, word stress.

Palavras-chave: consciência fonológica, prosódia, estrutura silábica, extensão de palavra, acento de palavra.

\section{Introdução}

A consciência fonológica tem sido estudada em Portugal com diferentes objetivos: uns autores procuram caracterizar a consciência fonológica enquanto tipo de conhecimento linguístico (Alves, Castro \& Correia, 2010; Antunes, 2013; Castro, Alves, Correia \& Soares, 2015; Cielo, 2001; Rios, 2009; Veloso, 2003, entre outros); outros detêm-se na observação de um constituinte fonológico específico, dando informação sobre o seu impacto nas taxas de sucesso de desempenho infantil (Afonso, 2008; Alves 2012; Cardoso, 2011; Castelo, 2012, entre outros); outros, ainda, têm testado o impacto de programas de treino da consciência fonológica (Carvalho, 2012; Fernandes, 2011; Ferreira, 2013; Lima \& Colaço, 2009, entre outros); por fim, alguns autores têm procurado construir provas que permitam avaliar

\footnotetext{
${ }^{1}$ A investigação foi desenvolvida no CLUL, no âmbito da tese de doutoramento da primeira autora, e financiada pela Fundação para a Ciência e a Tecnologia (referência UID/LIN/00214/2013).
} 
formalmente a consciência fonológica (Albuquerque, Martins \& Simões, 2007; Castro, Caló \& Gomes, 2007; Kay \& Santos, 2003; Silva, 2003; Sim-Sim, 2001).

Vários dos estudos supracitados controlam variáveis linguísticas como a estrutura silábica ou a extensão de palavra, mas não discutem o impacto que essas mesmas variáveis têm na realização das tarefas propostas.

Para o português europeu, existem já alguns estudos sobre o impacto da estrutura das unidades fonológicas na avaliação da consciência fonológica, seja no âmbito da consciência silábica (Jesus, 2008; Santana, 2008; Vasco, 2008), da consciência segmental (Afonso, 2008; Aparício, 2008; Silva, 2008; Alves 2012) ou da consciência intrassilábica (Barriguita, 2008; Meireles, 2008).

Tendo em conta o debate sobre o impacto que as variáveis fonológicas têm na realização de diferentes tarefas no domínio da consciência fonológica, colocamos a questão geral de investigação que se segue: A estrutura fonológica dos estímulos tem impacto no desempenho de tarefas de consciência fonológica? No sentido de responder à questão enunciada, observaremos o impacto das variáveis prosódicas extensão de palavra, complexidade silábica e padrão acentual num conjunto de tarefas de consciência fonológica (tarefas de segmentação, de identificação e de omissão silábica; tarefa de segmentação em segmentos; tarefa de segmentação dos constituintes silábicos), em dois grupos de crianças a frequentarem o $1^{\circ}$ Ciclo do Ensino Básico em Portugal (1. ${ }^{\circ}$ e $3 .^{\circ}$ anos).

\section{Metodologia}

Nesta secção, apresentam-se os aspetos metodológicos envolvidos no presente estudo: (i) seleção e caracterização da amostra; (ii) construção dos estímulos linguísticos usados nas tarefas aplicadas; (iii) procedimentos de aplicação das tarefas; (iv) tratamento dos dados.

\section{Seleção e caracterização da amostra}

As cinco provas foram aplicadas a dois grupos de estudo: 22 crianças que frequentavam o $1^{\circ}$ ano e 27 crianças que frequentavam o $3^{\circ}$ ano do $1^{\circ}$ Ciclo do Ensino Básico do Externato 
Flor do Campo (Ramada), perfazendo um total de 49 crianças $^{2}$. No Quadro 1, apresenta-se uma análise descritiva da amostra selecionada.

\begin{tabular}{lcc}
\hline \hline \multicolumn{1}{c}{ Grupo } & Média de Idades & Género \\
\hline Crianças 1..$^{\circ}$ ano & $6 ; 02$ & $6 \mathrm{~F} / 16 \mathrm{M}$ \\
Crianças 3..$^{\circ}$ ano & $8 ; 04$ & $9 \mathrm{~F} / 18 \mathrm{M}$ \\
\hline \hline
\end{tabular}

Quadro 1 - Distribuição da amostra de acordo com a idade e com o género.

Foram estabelecidos os seguintes critérios de inclusão de sujeitos na amostra constituída para o estudo:

(i) serem falantes monolingues de PE;

(ii) não terem perturbações da linguagem, cognitivas ou motoras que prejudicassem a realização da tarefa;

(iii) terem frequentado o ensino pré-escolar;

(iv) não beneficiarem de apoio em Terapia da Fala ou de apoio educativo.

\section{Estímulos linguísticos}

Assumindo-se como relevante que os estudos que avaliam a consciência fonológica tenham na base estímulos linguisticamente controlados, e na ausência de um instrumento fonologicamente controlado e disponível para o português europeu, procedeu-se à construção de um instrumento que contemplasse as variáveis fonológicas a analisar (extensão de palavra, padrão acentual; estrutura silábica; cf. Quadro 2, abaixo). Neste sentido, estabeleceram-se três critérios gerais para a seleção dos estímulos na totalidade das provas:

- $\quad$ Em todos os itens lexicais, exceto na sílaba-alvo, manipulada quanto à sua estrutura interna, presença de sílabas subsequentes do tipo $\mathrm{CV}$, como em olho, faca, braço, pêssego ou chocolate, dado este ser o padrão silábico mais frequente no português europeu (Andrade \& Viana, 1993; Vigário \& Falé, 1993), a estrutura não marcada nas línguas do mundo (Jakobson, 1941/68) e a primeira

\footnotetext{
${ }^{2}$ Foi realizado um estudo piloto com 20 crianças onde foram avaliadas as tarefas aplicadas neste estudo. Tendo em consideração os resultados obtidos para o tipo de tarefas e estruturas testadas foram eliminados os grupos do pré-escolar e do $4^{\circ}$ ano (para mais informações consulte-se Afonso, 2015).
} 
estrutura a ser adquirida no processo de desenvolvimento infantil (Bernhardt \& Stemberger, 1998; Fikkert, 1994; Freitas, 1997);

- $\quad$ uso de Nomes, por ser o paradigma de emergência precoce no desenvolvimento linguístico infantil (Guasti, 2002);

- $\quad$ uso de itens frequentes no léxico infantil (Freitas, 1997; Santos, Freitas \& Cardoso, 2014).

Posteriormente, estabeleceram-se critérios para a seleção dos estímulos subjacentes a cada uma das provas. Na prova de segmentação da palavra em sílabas, aplicaram-se os seguintes critérios:

- Uso de palavras com diferentes extensões (monossílabos, dissílabos, trissílabos e polissílabos);

- controlo da estrutura silábica dos estímulos ao nível do Ataque (palavras com Ataque vazio, simples e ramificado em posição inicial de palavra) e da Rima (palavras com Rima não ramificada e com Rima ramificada na sílaba inicial);

- uso de palavras paroxítonas e de palavras proparoxítonas, por corresponderem aos dois padrões de atribuição de acento em PE de acordo com a análise morfológica do acento (Mateus et al., 2006).

Para as provas de identificação silábica, omissão silábica e segmentação de palavras em segmentos, estabeleceram-se os seguintes critérios:

- $\quad$ uso de palavras dissilábicas, dado ser a extensão mais frequente no português europeu, tanto em adultos (Vigário, 2003; Vigário \& Falé, 1993) como em crianças (Vigário, Freitas \& Frota, 2006);

- $\quad$ escolha de palavras paroxítonas, sendo este o padrão acentual mais frequente no português europeu, no que se refere à classe dos Nomes, (Mateus \& Andrade, 2000; Mateus et al., 2006; Vigário, Martins \& Frota, 2006) e nos dados das primeiras produções infantis (Vigário, Freitas \& Frota, 2006);

- controlo da estrutura silábica dos estímulos ao nível do Ataque (palavras com Ataque vazio, simples e ramificado em posição inicial de palavra) e da Rima (palavras com Rima não ramificada e com Rima ramificada na sílaba inicial). 
Na prova de segmentação da palavra/sílaba em constituintes silábicos estabeleceram-se os seguintes critérios:

- $\quad$ introdução apenas de palavras monossilábicas, para evitar a ativação da segmentação silábica da palavra;

- utilização de palavras com ou Ataque ou Rima ramificados, no sentido de distinguir esta prova da prova de segmentação da palavra em segmentos.

Tendo por base os critérios fonológicos supracitados, foi construído o instrumento usado, com a estrutura apresentada no Quadro 2, onde se disponibilizam alguns exemplos ${ }^{3,4}$.

\begin{tabular}{|c|c|c|}
\hline Provas & Variáveis de Estudo & Exemplos \\
\hline \multirow{4}{*}{$\begin{array}{l}\text { - Segmentação } \\
\text { silábica }\end{array}$} & Extensão de palavra & $\begin{array}{l}\text { pá / pato / sapato / } \\
\text { capacete }\end{array}$ \\
\hline & $\begin{array}{l}\text { Estrutura silábica - } \\
\text { Ataque }\end{array}$ & $\begin{array}{l}\text { alho / carro / prato / } \\
\text { bloco }\end{array}$ \\
\hline & $\begin{array}{l}\text { Estrutura silábica - } \\
\text { Rima }\end{array}$ & polvo / pasta / porco \\
\hline & Padrão acentual & médico / sapato \\
\hline $\begin{array}{l}\text { - Identificação } \\
\text { silábica } \\
\text { - Omissão silábica } \\
\text { - Segmentação em } \\
\text { segmentos }\end{array}$ & $\begin{array}{l}\text { Estrutura silábica - } \\
\text { Ataque } \\
\text { Estrutura silábica - } \\
\text { Rima }\end{array}$ & $\begin{array}{l}\text { uva / bola / bruxa / blusa } \\
\text { balde / testa / garfo }\end{array}$ \\
\hline \multirow{3}{*}{$\begin{array}{l}\text { - Segmentação em } \\
\text { constituintes } \\
\text { silábicos }\end{array}$} & Extensão da palavra & sol \\
\hline & $\begin{array}{l}\text { Estrutura silábica - } \\
\text { Ataque }\end{array}$ & flor \\
\hline & $\begin{array}{l}\text { Estrutura silábica - } \\
\text { Rima }\end{array}$ & $d e z$ \\
\hline
\end{tabular}

Quadro 2 - Definição das variáveis de estudo na seleção dos estímulos nas diferentes provas de consciência fonológica.

\footnotetext{
${ }^{3}$ Instrumento disponível em www.clul.ulisboa.pt; para mais informações sobre o assunto, consulte-se Afonso, 2015.

${ }^{4}$ Para critérios de seleção das tarefas usadas neste estudo e para a avaliação do efeito de complexidade das diferentes tarefas consulte-se Afonso, 2015.
} 
Com base nos critérios mencionados anteriormente, foram selecionadas 54 palavras para a prova de segmentação silábica; 35 palavras para as provas de identificação silábica, de omissão silábica e de segmentação da palavra em segmentos; cinco palavras para a prova de segmentação da palavra/sílaba em constituintes silábicos. As palavras foram apresentadas sob a forma de estímulo áudio, para o que se utilizou o gravador MARANTZ ${ }^{5}$, e sob a forma de estímulo visual ${ }^{6}$. Relativamente aos estímulos áudio, depois de concluídas as gravações, todos os estímulos foram analisados acusticamente pela terapeuta da fala e investigadora Susana Rodrigues $^{7}$. Os estímulos visuais foram testados através da aplicação de uma prova de nomeação a um grupo de controlo.

\section{Procedimentos de aplicação}

As provas foram aplicadas aos grupos em estudo no decorrer dos meses de janeiro a junho de 2013, numa sala do estabelecimento de ensino frequentado pelas crianças.

Para a aplicação das provas, e disponibilizadas as autorizações pelos encarregados de educação, cada criança foi individualmente conduzida a uma sala isolada, tendo sido sentada diante do computador e ao lado do investigador. Em cima da mesa, estava colocada uma câmara de filmar, de forma a registar os movimentos dos dedos das crianças e as suas produções verbais. Cada criança foi informada de que a câmara de filmar estava a gravar as suas respostas, para que não se distraísse com a presença da mesma. Foram elaboradas folhas de registo para cada prova, tendo-se dito a cada criança que o investigador iria registar as suas respostas.

Para aplicação das tarefas, utilizou-se o programa E-prime 2.0 (Schneider, Eschman \& Zuccolotto, 2007), que permite manipular, em simultâneo, estímulos visuais, auditivos e gráficos. Na aplicação da tarefa de segmentação da palavra em sílabas, e tendo em consideração o número de itens (54 palavras), decidiu-se subdividir aleatoriamente a tarefa em duas subprovas para o grupo do $1^{\circ}$ ano. Em ambas as aplicações foram utilizados cinco itens de treino. Explicou-se aos sujeitos que iria surgir uma imagem no ecrã e que iriam ouvir simultaneamente uma palavra, solicitando-se que a dividissem em "bocadinhos" (sílabas), instrução também usada na aplicação do teste.

\footnotetext{
${ }^{5}$ Formato Stereo; PCM-24, 24 bit; $96 \mathrm{kHz}$.

${ }^{6}$ Todas as imagens foram desenhadas por um designer gráfico especificamente para este projeto.

${ }^{7}$ For realizada uma análise acústica através do programa PRAAT.
} 
A tarefa tinha início com um slide com o sinal de adição no ecrã do computador, para que a criança se preparasse para a realização da tarefa. Surgia, em seguida, a imagem da palavra e, passados 0,3 segundos, a criança ouvia a palavra-estímulo; terminada a apresentação do estímulo auditivo, a imagem alvo desaparecia do ecrã, após o que a criança começava a segmentar a palavra ouvida. Por cada sílaba identificada, a criança deveria carregar na tecla $Y$ (com a imagem do Nemo), aparecendo um traço horizontal preto no limite inferior do ecrã por cada vez que a criança premia a tecla; o objetivo era o de que criança tivesse feedback visual da sua decisão. Assim que a criança terminava a tarefa executada sobre a palavra ouvida, aparecia novamente no ecrã o sinal de adição. A metodologia descrita foi semelhante para as restantes tarefas, variando a instrução dada (prova de identificação silábica - "vais dizer o $1^{\circ}$ bocadinho de cada palavra"; prova de omissão silábica - "vais tirar o primeiro bocadinho da palavra e dizer o que fica"; prova de segmentação da palavra em segmentos - "vamos contar quantos sons têm as palavras"; prova de segmentação da sílaba/palavra em constituintes silábicos - "vamos dividir a palavra em partes") e os itens exemplificativos.

\section{Tratamento dos dados}

Os dados registados foram transcritos e foi criada uma base de dados no Excel que englobava as variáveis relacionadas com os dados pessoais das crianças e as variáveis relativas às respostas dadas: sucesso versus insucesso (sucesso cotado com 1 ponto; insucesso cotado com 0 pontos); identificação do erro para cada palavra incluída na prova (ex. alteração da estrutura silábica); análise dos valores de sucesso globais para a totalidade dos estímulos; análise dos valores de sucesso globais para cada uma das estruturas silábicas consideradas; análise dos valores de sucesso globais para as quatro extensões de palavra consideradas (apenas para a prova de segmentação silábica).

Para a análise dos resultados obtidos, utilizou-se o programa informático Statistical Package for the Social Sciences (SPSS) 17.0, tendo-se efetuado uma análise descritiva e inferencial por grupo e por variável em estudo. 


\section{Resultados}

Nesta secção, começamos por apresentar os resultados globais relativos à variável extensão de palavra, que apenas foi testada na prova de segmentação silábica (Gráfico 1).

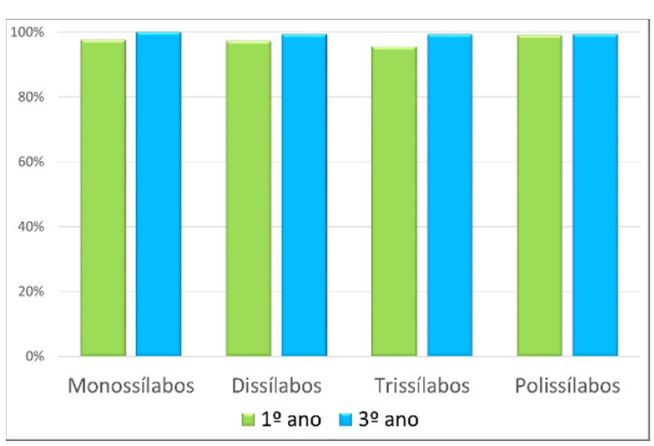

Gráfico 1 - Resultados da prova de segmentação silábica para a variável extensão de palavra.

Os resultados registados no Gráfico 1 revelam valores semelhantes para os dois grupos, sem diferenças significativas entre as quatros extensões estudadas (sig $>0,05)$. Analisando os dados por grupo, observa-se que o $1^{\circ}$ ano apresentou resultados ligeiramente inferiores na segmentação dos estímulos trissilábicos $(95,5 \%)$, mas sem diferenças estatisticamente significativas face às restantes extensões $(\operatorname{sig}>0,05)$.

Dado o objetivo da investigação e as variáveis em estudo, procedeu-se à mesma análise para a variável padrão acentual (Gráfico 2), a qual apenas foi testada na tarefa de segmentação silábica; a apresentação dos resultados é feita por grupo ( $1^{\circ}$ e $3^{\circ}$ anos $)$ e por tipo de padrão acentual (paroxítono e proparoxítono).

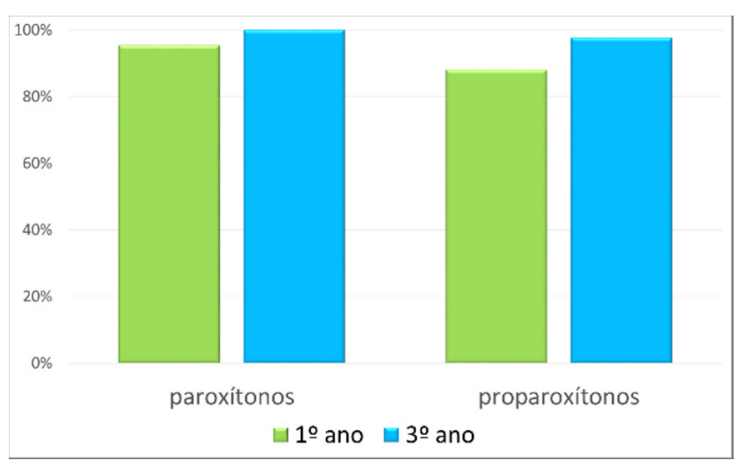

Gráfico 2 - Resultados da prova de segmentação silábica para a variável padrão acentual. 
Considerando os resultados apresentados no Gráfico 2, ambos os grupos obtiveram um desempenho semelhante na segmentação de palavras com controlo da variável acento de palavra, não se tendo observado diferenças estatisticamente significativas $($ sig $>0,05)$ para o grupo do $3^{\circ}$ ano. Registaram-se, porém, diferenças ligeiramente significativas para o grupo das crianças do $1^{\circ}$ ano (sig=0,023), registando-se uma maior dificuldade na segmentação dos trissílabos proparoxítonos, relativamente aos paroxítonos.

A variável estrutura silábica foi testada através da aplicação de quatro provas: identificação e de omissão silábica, de segmentação da palavra em segmentos e de segmentação da palavra/sílaba em constituintes silábicos. Tendo em consideração a natureza da última prova e o número de estímulos introduzidos na mesma, esta será analisada de forma isolada.

No Gráfico 3 apresentam-se os resultados globais de sucesso obtidos pelos dois grupos de estudo na realização das diferentes provas, tendo em consideração os itens com Ataque não ramificado (Ataque vazio e simples). Os resultados são apresentados por tipo de prova aplicada.

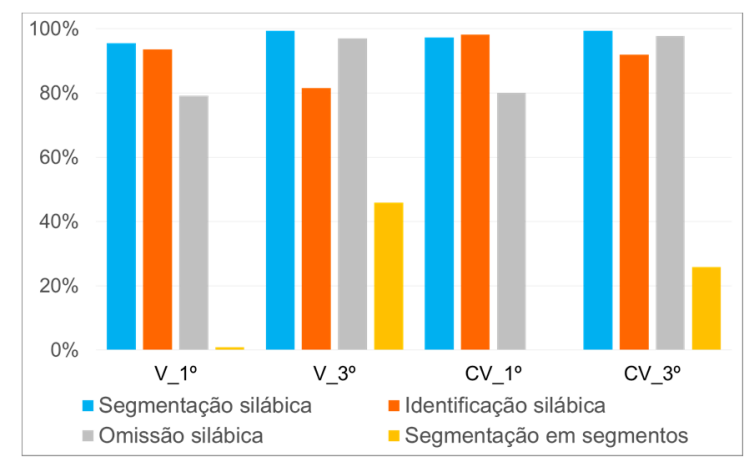

Gráfico 3 - Resultados por estrutura silábica (Ataque não ramificado) nas provas de identificação e de omissão silábica, de segmentação da palavra em segmentos e de segmentação da palavra/sílaba em constituintes silábicos.

No gráfico anterior, regista-se uma ausência de contraste significativo entre os estímulos com Ataque vazio e com Ataque simples, na maioria das provas. Inesperadamente, no $3^{\circ}$ ano, as crianças apresentaram mais dificuldades na identificação da sílaba inicial quando esta era do tipo 'V (81,5\%) do que quando era do tipo 'CV (91,9\%) (sig=0,010). Na prova de consciência segmental, as crianças do grupo do $3^{\circ}$ ano exibiram mais facilidade em segmentar palavras em segmentos quando estas apresentavam uma sílaba inicial do tipo ' $\mathrm{V}(45,9 \%)$ do que quando esta era do tipo 'CV $(25,9 \%)($ sig=0,045).

Em termos globais, o contraste é mais entre tipos de provas do que entre tipos de Ataque não ramificado, com resultados de sucesso sempre negativos (abaixo de 50\%) na prova de 
segmentação da palavra em segmentos (para avaliação do efeito de tipo de prova, consulte-se Afonso 2015).

Procedeu-se a uma análise semelhante à anterior para os estímulos com Ataque ramificado (Gráfico 4). Os resultados apresentados no gráfico que se segue estão organizados por grupo ( $1^{\circ}$ e $3^{\circ}$ anos), por tipo de prova e por tipo de Ataque ramificado (com lateral ou com vibrante como $\mathrm{C}_{2}$ ).

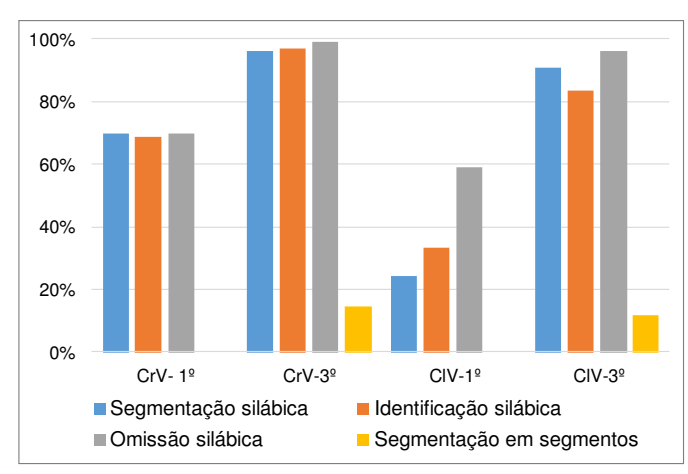

Gráfico 4 - Resultados por estrutura silábica (tipo de Ataque ramificado) nas provas de identificação e de omissão silábica, de segmentação da palavra em segmentos e de segmentação da palavra/sílaba em constituintes silábicos.

Tal como no Gráfico 3, volta a registar-se um contraste entre tipos de provas, com resultados de sucesso sempre negativos na prova de segmentação da palavra em segmentos. Há, no entanto, aspetos de natureza fonológica a destacar, que condicionam de forma significativa os resultados obtidos.

Assim, analisando o Gráfico 4, verifica-se que, independentemente da tarefa aplicada, quando o estímulo apresenta uma sílaba inicial do tipo ' $\mathrm{ClV}$ os resultados são mais baixos do que quando a sílaba inicial é do tipo ' $\mathrm{CrV}(\mathrm{sig}<0,05)$. Observam-se também valores globais mais baixos para as crianças do grupo do $1^{\circ}$ ano $(\operatorname{sig}<0,05)$, sendo esta estrutura bastante problemática para as crianças deste ano de escolaridade. Na prova de segmentação da palavra em segmentos, dado o elevado insucesso no desempenho das crianças, não foi possível testar um impacto do segmento em posição de $\mathrm{C}_{2}$, ainda que as crianças tenham apresentado dificuldades ligeiramente mais acentuadas na segmentação de palavras com o segmento [1] em $\mathrm{C}_{2}$ (11,9\% de sucesso) do que com o segmento [r] nessa mesma posição (14,8\% de sucesso).

O impacto da estrutura silábica dos itens também foi avaliado no que diz respeito ao tipo de Rima na sílaba inicial. No gráfico seguinte (Gráfico 5), ilustram-se os resultados obtidos 
nas quatro tarefas no que se refere aos estímulos com Rima ramificada, organizados também em função dos grupos escolares.

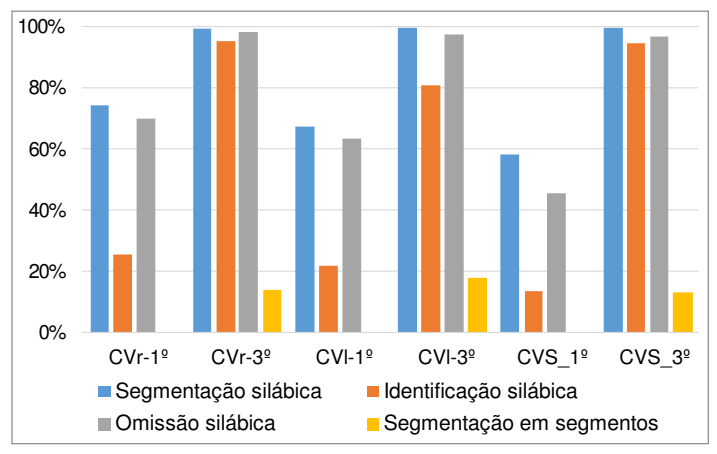

Gráfico 5 - Resultados por estrutura silábica (Rima ramificada) nas provas de identificação e de omissão silábica, de segmentação da palavra em segmentos e de segmentação da palavra/sílaba em constituintes silábicos.

O Gráfico 5 demonstra que, para o grupo do $1^{\circ}$ ano e em todas as provas aplicadas para a avaliação da sílaba, os estímulos com 'CVS inicial foram os mais difíceis de segmentar, de identificar e de omitir. Os estímulos com 'CVs e 'CVł iniciais apresentaram um comportamento semelhante, exceto na prova de identificação silábica para o grupo do $3^{\circ}$ ano. Na prova de segmentação da palavra em segmentos parece não existir um peso estatisticamente significativo no impacto do segmento em posição de Coda (sig $>0,05)$, ainda que tenham sido os estímulos com o segmento [S] em Coda os que apresentaram taxas de sucesso mais baixas. Uma vez mais, o elevado insucesso nesta prova impediu a observação do impacto da variável fonológica sob avaliação.

Por fim, apresentam-se isoladamente os resultados obtidos na prova de segmentação da palavra/sílaba em constituintes silábicos. Como referido anteriormente, e para evitar a segmentação silábica ou segmental dos estímulos lexicais selecionados para a prova, foi necessário optar pelo uso de monossílabos (cf. Rios, 2009) para opção idêntica) com estruturas silábicas complexas (com um ou mais constituintes ramificados), o que reduziu substancialmente as possibilidades de escolha de itens a usar (apenas 5). Assim, apresenta-se, no Gráfico 6, uma análise por palavra testada. 


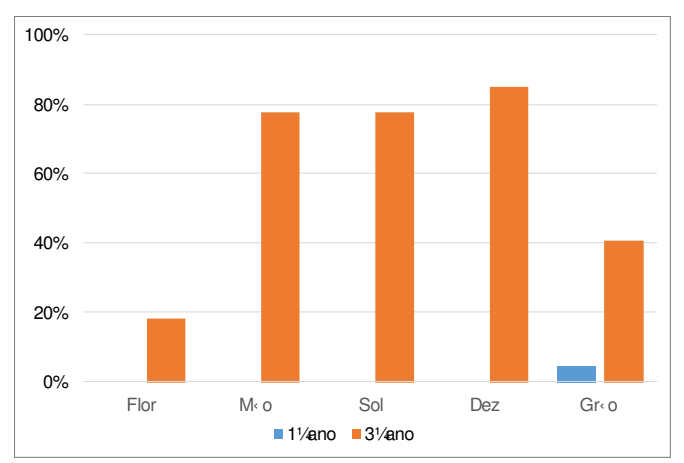

Gráfico 6 - Resultados por palavra (prova de consciência dos constituintes silábicos).

Note-se que, para o $1^{\circ}$ ano, a prova foi extremamente complexa e apenas na segmentação da palavra "grão" as crianças deste grupo realizaram a tarefa, ainda que com sucesso muito reduzido (4,5\%). Observando as taxas de sucesso das crianças do $3^{\circ}$ ano, verifica-se que o Ataque ramificado parece ter um peso significativo no desempenho das crianças, na medida em que os itens com esta estrutura foram os mais problemáticos na tarefa de segmentar a palavra/sílaba em Ataque/Rima. Já os estímulos com Rima ramificada, com estrutura do tipo $\left.\left[[\mathrm{C}]_{\text {Ataque }}[\mathrm{VG}]_{\text {Núcleo }}\right]_{\text {Rima }}\right]$, como mão, ou $\left.\left[[\mathrm{C}]_{\text {Ataque }}[\mathrm{V}]_{\text {Núcleo }} \mathrm{C}\right]_{\text {Rima }}\right]$, como dez ou sol, foram mais fáceis de segmentar para as crianças do $3^{\circ}$ ano. Aparentemente, o facto de a Rima ser ou não complexa (Rima ramificada em Núcleo + Coda; Núcleo Ramificado) parece não ter tido tanto impacto no desempenho das crianças do $3^{\circ}$ ano como o facto de o Ataque ser ou não complexo. Note-se, no entanto, que os resultados são escassos e carecem de confirmação empírica adicional.

\section{Considerações finais}

Neste trabalho, procurou-se testar o impacto de três variáveis fonológicas: extensão de palavra, padrão acentual e estrutura silábica, na realização de um conjunto de tarefas de consciência fonológica.

A variável extensão de palavra tem sido estudada essencialmente em tarefas de segmentação silábica e diferentes autores têm referido que as crianças tendem a segmentar mais facilmente estímulos dissilábicos, seguidos de estímulos trissilábicos e de estímulos monossilábicos (Afonso, 2008; Alves, Castro \& Correia, 2010; Cielo, 2001; Sim-Sim, 1997; Vasco, 2008; Vicente, 2009). No presente estudo não foi observado um impacto significativo 
da variável extensão de palavra na realização da tarefa proposta (segmentação silábica), ainda que se tenha verificado serem os estímulos trissilábicos ligeiramente mais complexos, quando comparados com as restantes extensões de palavra. A ausência de impacto estatisticamente significativo da variável extensão de palavra no presente estudo não era esperada tendo em conta os dados de frequência dos diferentes padrões no português europeu - dissílabos, 42,6\%, monossílabos, 19,8\%, e trissílabos, 18,4\% (Vigário, Martins \& Frota, 2004) e as tendências observadas nos estudos supracitados quanto à natureza facilitadora dos dissílabos na realização de provas de consciência fonológica.

Relativamente ao impacto da variável padrão acentual no contexto de avaliação da consciência fonológica, existem poucos estudos desenvolvidos para o português europeu; os que conhecemos referem que as palavras paroxítonas são mais fáceis de segmentar do que as palavras proparoxítonas (Afonso, 2008; Vicente, 2009). No presente estudo, os resultados foram bastante homogéneos para o grupo do $3^{\circ}$ ano, não se tendo observado um peso estatisticamente significativo da variável acento de palavra. No grupo do $1^{\circ}$ ano, observou-se uma ligeira diferença entre a segmentação de estímulos paroxítonos e proparoxítonos ( $\operatorname{sig}=0,023$ ), havendo taxas de sucesso mais baixas nos últimos, o que vai ao encontro dos dados de frequência para o português europeu, que referem o padrão proparoxítono como pouco frequente no sistema linguístico - padrão paroxítono, 76,4\%; padrão proparoxítono, 1,9\% (Mateus \& Andrade, 2000; Vigário, Martins \& Frota, 2006). Também os dados da aquisição do português europeu demonstram a aquisição precoce do acento, em geral, e do padrão paroxítono em particular (Correia, 2009; Correia, Costa \& Freitas, 2006; Vigário, Freitas \& Frota, 2006). No entanto, no presente estudo e em termos gerais, esta variável fonológica não teve um impacto estatisticamente significativo na realização da prova de segmentação silábica e mais estudos neste domínio são necessários para que se consiga testar a existência ou não do seu efeito na realização de provas de consciência fonológica. Note-se que têm sido realizados alguns trabalhos na área da aquisição e desenvolvimento fonológico em português europeu que procuram, entre outros aspetos, testar o efeito da variável acento de palavra; no entanto os resultados também ainda não são claros no que se refere à sua relevância na avaliação formal do desenvolvimento fonológico infantil, em contextos típico e atípico (Baptista, 2015; Correia, 2009; Nogueira, 2007).

Relativamente à variável estrutura silábica, as estruturas $\mathrm{CV}$ e V têm sido descritas como as mais fáceis de identificar, independentemente da faixa etária da amostra (Afonso, 
2008; Duncan, Colé \& Seymour, 2006; Vasco, 2008), seguidas das sílabas do tipo CCV (Afonso, 2008; Vasco, 2008; Veloso, 2003) e, por fim, das sílabas CVC e VC (Henriques, 2008; Resende, 2009; Vasco, 2008). De acordo com o trabalho de investigação realizado, as estruturas mais complexas, com Ataque e Rima ramificado, foram as mais difíceis de segmentar, identificar e omitir, efeito que tem sido também descrito nos dados de aquisição tanto para o português europeu (Almeida, 2011; Amorim, 2014; Freitas, 1997; Mendes et al., 2009/2013) como para outras línguas (Bernhardt \& Stemberger, 1998; Fikkert, 1994, 2005, 2007; Lamprecht et al., 2004; Rose, 2000).

Em relação aos estímulos com Ataque ramificado, o segmento em posição de $\mathrm{C}_{2}$ parece ter um peso significativo na realização das diferentes tarefas. Observou-se que tanto para as crianças do $1^{\circ}$ como como para as crianças do $3^{\circ}$ ano, os estímulos com o segmento lateral alveolar [1] naquela posição silábica tenderam a ser mais problemáticos. Este resultado vai ao encontro do que é descrito nos trabalhos de Amorim (2014), Mendes et al. (2009/2013), para a avaliação do conhecimento fonológico implícito, de Santos (2013), para a relação entre desenvolvimento fonológico e escrita, e de Veloso (2003, 2006), para a consciência fonológica. Esta dificuldade poderá estar relacionada com a forma como as crianças processam este tipo de sequências, sendo as duas consoantes do Ataque inicialmente processadas como heterossilábicas, passando a ser processadas como tautossilábicas apenas após a aprendizagem da ortografia (Veloso, 2003, 2006).

O constituinte Rima ramificada também parece permitir discriminar os dois grupos de estudo, tendo-se verificado, para todas as provas, diferenças no desempenho das crianças em função do segmento em posição de Coda. No geral, as Codas fricativas trouxeram mais dificuldades às crianças, o que não seria de esperar tendo em consideração os dados da aquisição, que mostram que segmentos fricativos em posição de Coda são o primeiro tipo de Coda a emergir e a estabilizar no desenvolvimento fonológico das crianças portuguesas (Almeida, 2011; Amorim, 2014; Freitas, 1997; Mendes et al., 2009/2013). Os resultados relatados no presente estudo vão, no entanto, ao encontro dos de Veloso (2003), também relativos à consciência fonológica na infância. Segundo este autor, a complexidade associada à fricativa em Coda deve-se ao facto de as duas consoantes adjacentes nas sequências de tipo JC em alvos do tipo 'CVS.CV estarem a ser intuitivamente processadas como tendo um estatuto tautossilábico ('CV.JCV), o que condicionaria o sucesso nas segmentações precoces deste tipo 
de estruturas. Uma outra justificação para este resultado poderá estar na natureza silábica distinta das consoantes em final de sílaba em português, sendo o segmento [S] representado como Coda e os segmentos $[\mathrm{r}] /[\exists]$ como membros de um Núcleo ramificado, como sugerido em Fikkert (1994), Freitas (1997) e Correia (2004).

Assim, e retomando a questão geral de investigação colocada na introdução, é possível afirmar que a estrutura silábica dos estímulos teve um impacto significativo na realização das diferentes tarefas de consciência fonológica aplicadas no presente estudo, tendo-se observado um grau de complexidade elevado na segmentação, na identificação e na omissão de estímulos com Ataque ramificado e com Rima ramificada, no grupo do $1^{\circ}$ ano, e na prova de segmentação de palavras em segmentos, no grupo do $3^{\circ}$ ano. Já os efeitos das variáveis extensão de palavra e acento de palavra não são claros, sendo necessários estudos adicionais que testem o impacto destas variáveis fonológicas na realização de diferentes tarefas no domínio da avaliação da consciência fonológica.

\section{Referências}

Afonso, C. (2008) Complexidade prosódica e segmentação de palavras em crianças entre os 4 e os 6 anos de idade. Dissertação de Mestrado em Terapia da Fala apresentada à Universidade Católica Portuguesa.

Afonso, C. (2015) Complexidade Prosódica - tarefas de consciência fonológica em crianças do $1^{o}$ Ciclo do Ensino Básico. Tese de Doutoramento em Linguística apresentada à Faculdade de Letras e Faculdade de Medicina da Universidade de Lisboa.

Albuquerque, C. P., Martins, C. \& Simões, M.R. (2007) Teste de consciência fonológica da bateria de avaliação neuropsicológica de coimbra. In. Temas e problemas: questões sobre o ensino e a aprendizagem da leitura e da escrita, 4 (2) (pp. 101-108). Edições Colibri.

Almeida, L. (2011) Acquisition de la Structure Syllabique en contexte de Bilinguisme Simultané Portugais-Français. Tese de Doutoramento apresentada à Faculdade de Letras da Universidade de Lisboa. 
Alves, D. (2012) Efeito das propriedades segmentais em tarefas de consciência segmental, de leitura e de escrita. Tese de Doutoramento apresentada à Faculdade de Letras da Universidade de Lisboa.

Alves, D., Castro, A. \& Correia, S. (2010) Consciência fonológica - dados sobre consciência fonémica, intrassilábica e silábica. Actas do XXV Encontro Nacional da Associação Portuguesa de Linguística, 169-184.

Amorim, C. (2014) Padrão de Aquisição de Contrastes do PE: a interação entre traços, segmentos e sílabas. Tese de Doutoramento apresentada à Faculdade de Letras da Universidade do Porto.

Andrade, E. \& Viana, M.C. (1993) Sinérese, diérese e estrutura silábica. Actas do IX Encontro Nacional da Associação Portuguesa de Linguística, 31-42.

Antunes, C. F. (2013) Caracterização do nível de consciência fonológica em crianças de idade pré-escolar. Tese de Mestrado em Desenvolvimento e Perturbações da Linguagem na Criança apresentada à Escola Superior de Saúde do Instituto Politécnico de Setúbal.

Aparício, A. (2008) Avaliação da Consciência Fonológica em crianças do $3^{\circ}$ ano de escolaridade numa escola da Freguesia da Quarteira. Monografia em Terapia da Fala apresentada à Escola Superior de Saúde da Universidade do Algarve.

Baptista, A.C. (2015) O desenvolvimento fonológico de crianças com otites médias com derrame: estudo longitudinal. Tese de Doutoramento em Linguística apresentada à Faculdade de Letras e Faculdade de Medicina da Universidade de Lisboa.

Barriguita, S.A.P. (2008) Consciência Intrassilábica dos Segmentos [ᄃ] e [1]/[ ł] em Crianças em Idade Escolar e Pré-Escolar. Monografia em Terapia da Fala apresentada à Escola Superior de Saúde Egas Moniz.

Bernhardt, B., \& Stemberger, J. (1998) Handbook of phonological development from the perspective of constraint-based nonlinear phonology. San Diego: Academic Press.

Cardoso, S. (2011). Consciência de palavra em crianças de idade pré-escolar e escolar. Tese de Mestrado em Desenvolvimento e Perturbações da Linguagem na Criança apresenta à Escola Superior de Saúde do Instituto Politécnico de Setúbal.

Carvalho, A. (2012) Avaliação de um programa para estimulação da consciência fonológica em contexto escolar. Tese de Mestrado em Didática da Língua Portuguesa apresentada Escola Superior de Educação de Lisboa. 
Castelo, A. (2012) Competência Metafonológica e Sistema Não Consonântico no Português Europeu: Descrição, Implicações e Aplicações para o Ensino do Português como Língua Materna. Tese de Doutoramento em Linguística Educacional apresentada à Faculdade de Letras da Universidade de Lisboa.

Castro, A.; Alves, D.; Correia, S. \& Soares, C. (2015) Avaliação da consciência fonológica: resultados de um estudo piloto. In A. Fiéis; A. Madeira \& M. Lobo (eds.). O Universal e o Particular. Uma Vida a Comparar. Homenagem a Maria Francisca Xavier. Lisboa: Edições Colibri. 95-102.

Castro, S. L; Caló, S. \& Gomes, I. (2007) Prova de avaliação da linguagem e da afasia em português. Lisboa: Cegoc.

Cielo, C. A. (2001). Habilidades em consciência fonológica em crianças de 4 a 8 anos de idade. Curso de pós-graduação em Letras apresentada à Universidade Católica do Rio Grande do Sul.

Correia, S. (2004) A aquisição de consoantes em final de sílaba no Português Europeu. Actas do XIX Encontro da Associação Portuguesa de Linguística, 397-408.

Correia, S. (2009) The Acquisition of Primary Word Stress in European Portuguese. Tese de Doutoramento apresentada à Faculdade de Letras da Universidade de Lisboa.

Correia, S., Costa, T. \& Freitas, M.J. (2006) Sobre o Pé e a aquisição do ponto de articulação no Português Europeu. Actas do XXII Encontro Nacional da Associação Portuguesa de Linguística, 273-285.

Duncan, L., Colé, P., Seymour, P., \& Magnan, A. (2006) Differing sequences of metaphonological development in French and English. Journal of Child Language, 33(2), 369-399.

Fernandes, T. F. M. (2011) Efeitos do treino da consciência fonológica em crianças préescolares, com e sem problemas de linguagem. Tese de Mestrado em Ciências da Educação apresentada à Escola Superior de Educação de Lisboa.

Ferreira, S. (2013) Intervenção em Consciência Fonológica: um contributo para colmatar a fratura entre o pré-escolar e o $1^{\circ}$ Ciclo. Tese de Doutoramento apresentada à Faculdade de Letras da Universidade do Porto.

Fikkert, P. (1994) On the acquisition of prosodic structure. Ph.D. Dissertation, HIL dissertations 6, Leiden University. The Hague: Holland Academic Graphics. 
Fikkert, P. (2005) From phonetic categories to phonological features specification: Acquiring the European Portuguese vowel system. Lingue e Linguaggio, 4(2), 263-280.

Fikkert, P. (2007) Acquiring phonology. In: P. de Lacy (ed.), Handbook of phonological theory. Cambridge. (pp. 537-554). MA: Cambridge University Press.

Freitas, M.J. (1997) Aquisição da estrutura silábica do Português Europeu. Tese de Doutoramento em Linguística Aplicada apresentada à Faculdade de Letras da Universidade de Lisboa.

Guasti, M. T. (2002) Language acquisition: The growth of grammar. MIT Press.

Henriques, M. I. (2008) Produção e Segmentação de Palavras Iniciadas pelas Sequências Gráficas “es $+C$ ” $e$ "ex+C" em Falantes do Português. Dissertação de Mestrado apresentada à Faculdade de Letras da Universidade do Porto.

Jakobson, R. (1941/1968) Child Language, Aphasia and Phonological Universais. The Hague: Mouton.

Jesus, M. A. (2008) Identificação de sílaba inicial em crianças de idade escolar e pré-escolar. Monografia em Terapia da Fala apresentada à Escola Superior de Saúde do Instituto Politécnico de Setúbal.

Kay, S. \& Santos, M.E. (2003) Grelha de observação da linguagem - nível escolar. Alcoitão: Escola Superior de Saúde.

Lamprecht, R.R., Bonilha, G.F., Freitas, G.C., Matzenauer, C.L., Mezzono, C.L., Oliveira, C.C. \& Ribas, L.P. (2004) Aquisição fonológica do Português: perfil de desenvolvimento e subsídios para terapia. Porto Alegre: Artmed Editora.

Lima, R.M. \& Colaço, C.S.P.T.F. (2009) Falantes conscientes, leitores competentes. Exedra: Revista Científica, 1, 245-256.

Mateus, M. H., \& d'Andrade, E. (2000) The phonology of Portuguese. Oxford University Press. Mateus, M.H., Brito, A.M., Duarte, I., Faria, I.H., Frota, S., Matos, G., Oliveira, F., Vigário, M. \& Villalva, A. (2006) Gramática da língua portuguesa (7 $7^{\mathrm{a}}$ edição). Lisboa: Editorial Caminho.

Meireles, A.C. (2008) Consciência Intrassilábica da Coda em Tarefas de Segmentação Silábica. Monografia em Terapia da Fala apresentado à Escola Superior de Saúde Egas Moniz.

Mendes, A., Afonso, C., Lousada, M. \& Andrade, F. (2009/2013) Teste Fonético- Fonológico da Avaliação da Linguagem pré-escolar - ALPE. Designeed, Lda. 
Nogueira, P. (2007) Desenvolvimento fonológico em crianças dos 3 anos e 6 meses aos 4 anos e 6 meses de idade nascidas com muito baixo peso. Dissertação de Mestrado em Ciências da Fala apresentada à Universidade Católica Portuguesa.

Resende, A.M. (2009) Desenvolvimento da Consciência Fonológica em Português. Tese de Mestrado Integrado em Psicologia apresentada à Faculdade de Psicologia e de Ciências da Educação da Universidade do Porto.

Rios, A.C. (2009) Competências fonológicas na transição do pré-escolar para o $1^{\circ}$ Ciclo do ensino básico. Tese de Mestrado em Ciências da Fala e da Audição apresentada à Universidade de Aveiro.

Rose, Y. (2000) Headedness and Prosodic Licensing in the L1 Acquisition of Phonology. PhD, McGill University, Montréal.

Santana, I. (2008) Exclusão Silábica em crianças de idade escolar e pré-escolar. Monografia em Terapia da Fala apresentada à Escola Superior de Saúde do Instituto Politécnico de Setúbal.

Santos, A.C., Freitas, M.J. \& Cardoso, A. (2014) CEPLEXicon - A Lexicon of Child European Portuguese. Lisboa: Anagrama (CLUL, FLUL).

Santos, R. (2013) Aquisição de grupos consonânticos e seu impacto nos desempenhos escritos no $1^{o}$ Ciclo do Ensino Básico. Tese de Mestrado apresentada à Faculdade de Letras da Universidade de Lisboa.

Schneider, W., Eschman, A., \& Zuccolotto, A. (2012) E-Prime User's Guide. Pittsburgh: Psychology Software Tools, Inc.

Silva, A.C. (2003) Até à descoberta do princípio alfabético. Lisboa: Fundação Calouste Gulbenkian.

Silva, A.C. (2008) Avaliação da consciência fonémica em crianças do $1^{\circ}$ Ciclo $-1^{o}$ ano, de uma escola de Faro - provas de segmentação e síntese fonémica. Monografia em Terapia da Fala apresentada à Escola Superior de Saúde do Algarve.

Sim-Sim, I. (2001) Avaliação da Linguagem Oral: um contributo para o conhecimento do desenvolvimento linguístico das crianças portuguesas. Lisboa: Fundação Calouste Gulbenkian.

Vasco, J. (2008) Segmentação silábica em crianças em idade escolar e pré-escolar: dos quatro anos e seis meses aos sete anos e cinco meses de idade. Monografia em Terapia da Fala apresentada à Escola Superior de Saúde do Instituto Politécnico de Setúbal. 
Veloso, J.M. (2003) Da influência do conhecimento ortográfico sobre o conhecimento fonológico - estudo longitudinal de um grupo de crianças falantes nativas do Português Europeu. Tese de Doutoramento em Linguística apresentada à Faculdade de Letras da Universidade do Porto.

Veloso, J.M. (2006) Reavaliando o estatuto silábico das sequências Obstruinte+Lateral em Português Europeu. D.E.L.T.A - Revista de Documentação de Estudos em Linguística Teórica e Aplicada, 22 (1), 127-158.

Vicente, F. (2009) Consciência fonológica no ensino básico em Moçambique. Tese de Mestrado em Linguística apresentada à Faculdade de Letras da Universidade de Lisboa.

Vigário, M. \& Falé, I. (1993) A sílaba do Português Fundamental: uma descrição e algumas considerações de ordem teórica. Actas do IX Encontro Nacional da Associação Portuguesa de Linguística, 465-478.

Vigário, M., Freitas, M.J. \& Frota, S. (2006) Grammar and frequency effects in the acquisition of prosodic words in European Portuguese. Language and Speech, 49(2), 175-203.

Vigário, M., Martins, F. \& Frota, S. (2004) Frequências no Português Europeu: a ferramenta FreP. Actas do XX Encontro Nacional da Associação Portuguesa de Linguística, 897908.

Vigário, M., Martins, F. \& Frota, S. (2006) A ferramenta FreP e a frequência de tipos silábicos e classes de segmentos no Português. Actas do XXI Encontro Nacional da Associação Portuguesa de Linguística, 675-687. 